\title{
Surgical management of submacular hemorrhage due to n-AMD: a comparison of three surgical methods
}

\author{
Carsten Grohmann ${ }^{1 *}$ (D) Spyridon Dimopoulos ${ }^{2 \dagger}$, Karl Ulrich Bartz-Schmidt ${ }^{2}$, Philipp Schindler ${ }^{1}$, Toam Katz ${ }^{1}$, \\ Martin S. Spitzer ${ }^{1}$ and Christos Skevas ${ }^{1}$
}

\begin{abstract}
Background: To compare and assess the efficacy of three surgical methods for the treatment of acute submacular hemorrhage (ASH): pneumatic displacement with C2F6, in combination with intravitreal injection of bevacizumab and rtPA, pars plana vitrectomy (PPV) with intravitreal injection of gas (C2F6), bevacizumab and subretinal injection of recombinant tissue plasminogen activator (rtPA), pars plana vitrectomy (PPV) with intravitreal injection of gas (C2F6), bevacizumab and intravitreal injection of recombinant tissue plasminogen activator (rtPA).

Methods: The study included 85 patients with ASH. In the group without PPV (A), patients were treated with intravitreal injection of $\mathrm{C} 2 \mathrm{~F} 6$, bevacizumab and rtPA. In the second and third group, patients underwent a PPV, intravitreal injection of bevacizumab, pneumatic displacement with C2F6 and a subretinal (B) or intravitreal (C) injection of recombinant tissue plasminogen activator (rt PA).
\end{abstract}

Results: In group A, mean BCVA increased from preop logMAR 1.41 to 1.05, in group B from 1.46 to 1.28 and in group C from 1.63 to 1.33. In group A, CFT changed from $764 \pm 340 \mu \mathrm{m}$ at time point 0 to $246 \pm 153 \mu \mathrm{m}$ at time point 1 , in group B from $987 \pm 441 \mu \mathrm{m}$ to $294 \pm 166 \mu \mathrm{m}$ and in group C from $642 \pm 322 \mu \mathrm{m}$ to $418 \pm 364 \mu \mathrm{m}$. Patients had an average of 5 injections after surgery.

Conclusion: Our study demonstrates that the three methods are equally effective in improving the morphology and the BCVA of patients with ASH.

Keywords: Acute submacular hemorrhage (ASH), Neovascular age related macular degeneration (n-AMD), Choroidal neovascularization (CNV), Vascular endothelial growth factor (VEGF), Retinal pigment epithelium (RPE), Central foveal thickness (CFT), Pars plana vitrectomy (PPV), Recombinant tissue plasminogen activator (rtPA)

*Correspondence: c.grohmann@uke.de

${ }^{\dagger}$ Carsten Grohmann and Spyridon Dimopoulos contributed equally to this work

${ }^{1}$ Department of Ophthalmology, University Medical Center HamburgEppendorf (UKE), Hamburg, Germany

Full list of author information is available at the end of the article

\begin{abstract}
Background
A devastating complication of a n-AMD is an acute submacular hemorrhage (ASH) [1]

The localization of the hemorrhage may vary between the neurosensory retina and the RPE or beneath the RPE. The harmful consequences on the retina can be attributed to a limited passage of nutrients, the shrinkage of the outer retinal layers due to clot formation and the release of toxic substances like iron, hemosiderin and fibrin. Toxic effects of subretinal blood can be demonstrated $24 \mathrm{~h}$ after hemorrhage [2-6].
\end{abstract}

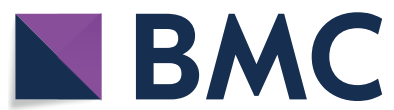

(c) The Author(s) 2020. This article is licensed under a Creative Commons Attribution 4.0 International License, which permits use, sharing, adaptation, distribution and reproduction in any medium or format, as long as you give appropriate credit to the original author(s) and the source, provide a link to the Creative Commons licence, and indicate if changes were made. The images or other third party material in this article are included in the article's Creative Commons licence, unless indicated otherwise in a credit line to the material. If material is not included in the article's Creative Commons licence and your intended use is not permitted by statutory regulation or exceeds the permitted use, you will need to obtain permission directly from the copyright holder. To view a copy of this licence, visit http://creativecommons.org/licenses/by/4.0/. The Creative Commons Public Domain Dedication waiver (http://creativecommons.org/publicdomain/zero/1.0/) applies to the data made available in this article, unless otherwise stated in a credit line to the data. 
Prognosis of an untreated choroidal neovascularization (CNV), which is also complicated by an $\mathrm{ASH}$, is poor and can lead to permanent vision loss. The underlying $\mathrm{CNV}$ may progress, and the resolution of the hemorrhage leads to a macular scar formation $[1,7-10]$.

Other causes that can lead to an ASH are high myopia, trauma and arterial macroaneurysm. Duration of the bleeding, size of the hemorrhage and thickness of the blood clot, among other factors, can play a decisive role in the visual prognosis [11].

To date, there is no standardized treatment protocol for ASH due to n-AMD, but a variety of therapeutic approaches have been described. The common goal of all those treatment options is the rapid displacement of submacular/subretinal blood from the fovea in order to prevent damage to the photoreceptors [11]. These include intravitreal administration of gas, intravitreal or subretinal application of recombinant tissue plasminogen activator (rt-PA), intravitreal injection of anti-VEGF substances, pars plana vitrectomy (PPV) and subretinal clot removal [12].

The evolution of these new treatment modalities gave hope to many patients whose prognosis might be dire and paved the way for a discussion among surgeons and authors about which surgical therapy is more effective and advantageous for the patients. The purpose of this study is to address this question. Principal outcome measures were displacement of hemorrhage, complications, best corrected visual acuity (BCVA) and central foveal thickness (CFT).

\section{Methods}

Our study was retrospective in nature and included a total number of 85 patients treated at the university clinic Eppendorf in Hamburg and Eberhard Carls in Tübingen, Germany. The investigation adhered to the tenets of the declaration of Helsinki. The etiology of the ASH in our patients was n-AMD in all cases. Exclusion criteria were massive submacular hemorrhages extending beyond the equator, RPE detachments and sub-RPE bleedings, macular scar, polypoidal choroidal vasculopathy and other etiology for ASH like high myopia, trauma and arterial macroaneurysm. Before initiating treatment, all strategies were thoroughly discussed with the patients, along with the possibility of no treatment as none of the offered treatment modalities are clearly evidence based. All patients rejected the no-treatment option.

Our study included three groups of surgical treatment.

In the first group (group A) in which no PPV was performed, patients were treated with intravitreal injection of C2F6 (Hexafluorethan-16\%) gas, $1.25 \mathrm{mg}$ of bevacizumab and recombinant tissue plasminogen activator (rtPA) $\left(20 \mu \mathrm{g}(0.1 \mathrm{ml})\right.$. [Rt-PA (Actilyse ${ }^{\circledR}$,
Boehringer Ingelheim, Ingelheim, Germany)]. Group A included 32 patients. The mean extent of the hemorrhage in this group was 4.4 $\pm 1.8 \mathrm{PD}$ [papillary diameter (PD)].

In the second and third group (groups $\mathrm{B}$ and $\mathrm{C}$ ), patients underwent a standard three-port PPV (23G), intravitreal injection of $1.25 \mathrm{mg}$ bevacizumab, pneumatic displacement with C2F6 (Hexafluorethan-16\%) gas and injection of $\mathrm{rt}$ PA. The difference between groups $B$ and $C$ is that in group $B$ patients received $r$ PA subretinally $(20 \mu \mathrm{g}(0.1 \mathrm{ml}))$ and in group $C$ intravitreally $(20 \mu \mathrm{g}(0.1 \mathrm{ml}))$. The injection of rt PA into the subretinal space was performed utilizing a $41 \mathrm{G}$ transretinal needle. A subretinal bleb was created in order to bathe the entire clot and to allow for optimal displacement of the hemorrhage. Following rtPA injection, air-fluid and air-gas exchange was performed. The mean PD of the hemorrhage in group B was $4.14 \pm 1.3 \mathrm{PD}$ and in group $\mathrm{C}$ $4.68 \pm 2.8$ PD.

Group B included 42 patients, and group C included 11 patients.

In all treatment groups, patients were instructed to keep a prone position for at least 7 days postoperatively. All patients were advised to attend our institution for follow-up examinations.

Principal outcome measures were displacement of hemorrhage, BCVA, CFT and complications (intraoperative and postoperative). Preoperative and postoperative evaluation included a complete ocular examination comprised of a slitlamp examination (anterior and posterior chamber evaluation), BCVA, intraocular pressure measurement, CFT with spectral domain optical coherence tomography [SD-OCT (Heidelberg Spectralis; Heidelberg Engineering, Heidelberg, Germany)] and fluorescein angiography (FLA).

The average interval from the onset of symptoms to surgery was $9.1 \pm 4.6$ days. Surgery was performed the day after preoperative examination (time point 0 ), and the last evaluation follow-up was 6 months after surgery (time point 1).

All patients fully acknowledged the potential risks and all possible postoperative consequences before surgery. Written informed consent was obtained from each patient and his or her family members after discussion of the procedure.

For statistical analyses, BCVA was analyzed on a logarithm of the minimum angle of resolution (logMAR) scale. In the current study, visual acuity of counting fingers and hand motion was converted as 2.0 and 3.0 logMAR, respectively.

\section{Statistical analysis}

All data were expressed as mean \pm standard deviation and compared using the Wilcoxon Signed-Rank Test, 
ANOVA-type statistics and the pairwise Mann-Whitney test. Statistical analyses were performed using SPSS 19.0 software. Statistical significance was considered when $\mathrm{p}<0.05$

\section{Results}

Our study included 32 men and 53 women. The mean patient age was 85.36 years (range 53-102 years). The mean follow-up period was 6.1 months (range 5-7 months).

\section{Postoperative visual outcome}

In group $\mathrm{A}$, mean BCVA was preop $\log \mathrm{MAR}$ $1.41[(\mathrm{SD})=0.48]$ and postop $1.05[(\mathrm{SD}=0.52)]$. BCVA improved in 22, remained unchanged in 3 and decreased in 7 patients.

In group $\mathrm{B}$, mean BCVA was preop $\log \mathrm{MAR} 1.46$ $[(\mathrm{SD})=0.54]$ and postop $1.28 \quad[(\mathrm{SD}=0.61)]$. BCVA improved in 23, remained unchanged in 7 and decreased in 12 patients.

In group $\mathrm{C}$, mean BCVA was preop $\log \mathrm{MAR} 1.63$ $[(\mathrm{SD})=0.53]$ and postop $1.33[(\mathrm{SD}=0.59)]$.

BCVA improved in 6, remained unchanged in 2 and decreased in 3 patients.

Table 1 shows the descriptive statistics for the BCVA and the macular thickness at the preoperative timepoint. Table 2 shows the descriptive statistics at the timepoint of the 6 months follow-up. The statistics for the visual outcome can be found in Table 3. BCVA did not differ significantly between the three groups, neither at the preoperative nor at the postoperative time point, which shows that BCVA improved significantly only in groups $\mathrm{C}$ and $\mathrm{A}$, with $\mathrm{p}=0.013$ and $\mathrm{p}=0.001$ respectively. Ranks and Relative Effects confirm this result: ranks in group $B$ are very similar at each time point, and RTEs (relative treatment effects) are all around 0.5. No main effect of one of the three groups was observed (the BCVA in all three groups is similar); there is overall significant improvement in BCVA (We saw, however, that this overall effect is mainly due to the improvements in groups $\mathrm{A}$ and $\mathrm{C}$.). There is no interaction between time and groups.

The data suggests that the BCVA among the three groups is not statistically significant at time point 0 (preop) and time point 1 (6 months post-op).

\section{Complications}

There were no intraoperative complications. There were two retinal detachments (one in the group with intravitreal injection and one in the group of the PPV with intravitreal injection of rtPA). There were no cases of infectious endophthalmitis.

\section{Anatomical outcome}

In group A, CFT changed from $764 \pm 340 \mu \mathrm{m}$ at baseline to $246 \pm 153 \mu \mathrm{m}$ at 6 months.

In group B, CFT changed from $987 \pm 441 \mu \mathrm{m}$ at baseline to $294 \pm 166 \mu \mathrm{m}$ at 6 months.

In group C, CFT changed from $642 \pm 322 \mu \mathrm{m}$ at baseline to $418 \pm 364 \mu \mathrm{m}$ at 6 months.

Table 1 Descriptive statistics for Visus and macular thickness (in $\mu \mathrm{m}$ ) preoperative

\begin{tabular}{llllllllll}
\hline Groups & Type & N & Mean & SD & Lower & Upper & Median & Q25 & Q75 \\
\hline A & Visus & 34 & 1.41 & 0.48 & 1.26 & 1.57 & 1.3 & 1.02 & 2.03 \\
A & Macular & 32 & 764 & 340 & 656 & 886 & 715 & 535 \\
B & Visus & 47 & 1.46 & 0.54 & 1.30 & 1.61 & 1.4 & 1.00 \\
B & Macular & 42 & 987 & 441 & 857 & 1120 & 890 & 2.10 \\
C & Visus & 23 & 1.63 & 0.53 & 1.40 & 1.83 & 1.8 & 1200 \\
C & Macular & 11 & 642 & 322 & 473 & 845 & 599 & 1.30 & 2.10 \\
\hline
\end{tabular}

Table 2 Descriptive statistics for Visus and macular thickness (in $\mu \mathrm{m}$ ) at the time of follow up (6 months, postop)

\begin{tabular}{llllllllll}
\hline Groups & Time & N & Mean & SD & Lower & Upper & Median & Q25 & Q75 \\
\hline A & Visus & 34 & 1.05 & 0.52 & 0.88 & 1.22 & 1.0 & 0.62 & 1.53 \\
A & Macular & 32 & 246 & 135 & 204 & 297 & 208 & 189 \\
B & Visus & 47 & 1.28 & 0.61 & 1.11 & 1.46 & 1.3 & 310 \\
B & Macular & 42 & 294 & 166 & 246 & 343 & 281 & 1.90 & 1.70 \\
C & Visus & 23 & 1.33 & 0.59 & 1.09 & 1.57 & 1.2 & 170 \\
C & Macular & 11 & 418 & 365 & 250 & 663 & 266 & 252 & 440 \\
\hline
\end{tabular}


Table 3 Analytical statistics (Kruskal-Wallis test, Wilcoxon signed rank test, ANOVA-type statistics and rank statistics) for Visus preoperative and at the time of follow up ( 6 months, postop)

\begin{tabular}{|c|c|c|c|c|c|c|c|c|c|}
\hline Groups & Time & $\mathrm{DF}$ & V/Stat. & $\mathrm{Chi}^{2}$ & $p$ & Rank means & $\mathbf{N}$ & RTE & type \\
\hline A & - & - & 389.5 & - & 0.013 & - & - & - & Wilcox \\
\hline B & - & - & 527.0 & - & 0.057 & - & - & - & Wilcox \\
\hline C & - & - & 129.5 & - & 0.013 & - & - & - & Wilcox \\
\hline- & Preop & 2 & - & 2.41 & 0.300 & - & - & - & Kruskal \\
\hline- & Postop & 2 & - & 4.13 & 0.127 & - & - & - & Kruskal \\
\hline Groups & - & 1.81 & 2.20 & - & 0.116 & - & - & - & ANOVA \\
\hline- & Time & 1.00 & 21.54 & - & 0.000 & - & - & - & ANOVA \\
\hline Groups & Time & 2.00 & 0.84 & - & 0.432 & - & - & - & ANOVA \\
\hline A & - & - & - & - & - & 92 & 68 & 0.44 & Rank \\
\hline B & - & - & - & - & - & 107 & 94 & 0.51 & Rank \\
\hline C & - & - & - & - & - & 118 & 46 & 0.56 & Rank \\
\hline- & Preop & - & - & - & - & 120 & 104 & 0.58 & Rank \\
\hline - & Postop & - & - & - & - & 91 & 104 & 0.44 & Rank \\
\hline A & Preop & - & - & - & - & 111 & 34 & 0.53 & Rank \\
\hline A & Postop & - & - & - & - & 73 & 34 & 0.35 & Rank \\
\hline B & Preop & - & - & - & - & 116 & 47 & 0.55 & Rank \\
\hline B & Postop & - & - & - & - & 98 & 47 & 0.47 & Rank \\
\hline C & Preop & - & - & - & - & 133 & 23 & 0.64 & Rank \\
\hline C & Postop & - & - & - & - & 102 & 23 & 0.49 & Rank \\
\hline
\end{tabular}

Patients, on average, had 5 injections after surgery, given in monthly intervals after surgery ( 0 to 9 injections; bevacizumab). The re-treatment criteria were signs of CNV activity seen on OCT or angiography. Tables 1 and 2 show the descriptive statistics for BCVA. In group $\mathrm{A}, 4$ out of 32 patients did not receive intravitreal injections after surgery. In group B, 7 out of 42 patients, and in group $C$ only 3 out of 11 did not receive intravitreal injections after surgery. Most patients received a series of three anti-VEGF injections every 4 weeks followed by a treat-and-extend scheme.

In Table 4, the analytical statistics of the different groups for the macular thickness are shown. KruskalWallis test confirmed that there were significant differences between the groups at time point 0 but not at time point 1 . There was only a significant difference between groups $B$ and $C$. This rank-based approach tests the main effects of groups and time and allows for the testing of interaction terms. First, let us look at mean ranks and the relative effects associated with groups, occasions and their interactions.

We see the ranks for group $C$, followed by group B and group A. So, taking all measurements together (both occasions), group $C$ had higher values compared to the other two groups. These differences were not large.

Indeed, relative effects were all around 0.5. For instance, the relative effect (RTE) 0.53 for group B (PPV with rt PA subretinal) can be interpreted as follows: a randomly chosen observation from the whole dataset results in a smaller value than a randomly chosen observation from group B (PPV with rt PA subretinal) with an estimated probability of $53 \%$. So, nearly $50 \%$ of the patients have lower or higher values on macular thickness than a randomly selected patient from group $\mathrm{B}$ (PPV with rt PA subretinal). In other words, there is no difference between the patients from this group and those from the others. The effect of groups is not statistically significant, $p=0.267$. On the other hand, the main effect of time is highly significant, $\mathrm{p}<0.001$. From Table 4 we see that the probability that the randomly chosen observation from the whole dataset will have a smaller value on retinal thickness than a randomly selected patient on the second occasion is only $30 \%$. This means that there is a significant decrease of macular thickness from time point 0 to time point 1 , and this tells us that there is overall a significant interaction between groups and time points. We can fit separate ANOVA-type models to investigate the interactions between groups and measurement time. We see that while there was an overall significant interaction, the pairwise comparisons lacked a statistically significant effect (at a 0.05 level). Thus, the interaction should be confirmed by sampling more data.

The mean interval from the onset of symptoms to surgery was $9.1 \pm 4.6$ days, and the average size of the subretinal hemorrhage was $4.5 \pm 1.0$ disc diameters. The 
Table 4 Analytical statistics (Kruskal-Wallis test, Wilcoxon signed rank test, ANOVA-type statistics and rank statistics, interaction contrasts and pairwise Mann-Whitney-Test) for macular thickness preoperative and at the time of follow up (6 months, postop)

\begin{tabular}{|c|c|c|c|c|c|c|c|c|c|}
\hline Groups & Time & $\mathrm{DF}$ & V/Stat. & $\mathrm{Chi}^{2}$ & $p$ & Rank means & $\mathrm{N}$ & RTE & Type \\
\hline A & - & - & 526 & - & 0.000 & - & - & - & Wilcox \\
\hline B & - & - & 894 & - & 0.000 & - & - & - & Wilcox \\
\hline C & - & - & 50 & - & 0.147 & - & - & - & Wilcox \\
\hline- & Preop & 2 & - & 9.46 & 0.009 & - & - & - & Kruskal \\
\hline- & Postop & 2 & - & 3.28 & 0.194 & - & - & - & Kruskal \\
\hline Groups & - & 1.53 & 1.30 & - & 0.267 & - & - & - & ANOVA \\
\hline- & Time & 1.00 & 103.68 & - & 0.000 & - & - & - & ANOVA \\
\hline Groups & Time & 1.40 & 4.72 & - & 0.018 & - & - & - & ANOVA \\
\hline A & - & - & - & - & - & 79 & 64 & 0.46 & Rank \\
\hline B & - & - & - & - & - & 91 & 84 & 0.53 & Rank \\
\hline C & - & - & - & - & - & 84 & 22 & 0.49 & Rank \\
\hline- & Preop & - & - & - & - & 118 & 85 & 0.69 & Rank \\
\hline- & Postop & - & - & - & - & 52 & 85 & 0.30 & Rank \\
\hline A & Preop & - & - & - & - & 117 & 32 & 0.68 & Rank \\
\hline A & Postop & - & - & - & - & 41 & 32 & 0.24 & Rank \\
\hline B & Preop & - & - & - & - & 133 & 42 & 0.78 & Rank \\
\hline B & Postop & - & - & - & - & 49 & 42 & 0.29 & Rank \\
\hline C & Preop & - & - & - & - & 103 & 11 & 0.61 & Rank \\
\hline C & Postop & - & - & - & - & 41 & 11 & 0.38 & Rank \\
\hline$A: B$ & - & - & - & - & 0.079 & - & - & - & Pairwise \\
\hline$A: C$ & - & - & - & - & 0.587 & - & - & - & Pairwise \\
\hline$B: C$ & - & - & - & - & 0.028 & - & - & - & Pairwise \\
\hline B:A & Pre:Post & - & - & - & 1.000 & - & - & - & Interact \\
\hline$C: B$ & Pre:Post & - & - & - & 0.51 & - & - & - & Interact \\
\hline$C: A$ & Pre:Post & - & - & - & 0.081 & - & - & - & Interact \\
\hline
\end{tabular}

submacular hemorrhage was displaced from the foveal area in all eyes after 1 week.

\section{Discussion}

ASH is a common manifestation of n-AMD. It is associated with sudden visual loss, and the prognosis of ASH is often poor. The reduced visual outcome is caused by retinal toxicity of subretinal blood, which includes limited diffusion of nutrients and oxygen, damaging photoreceptor outer segments due to clot contraction and release of toxic materials. The functional outcome may also be influenced by the duration and the size of submacular hemorrhage. Time is believed to be of essence in treating $\mathrm{ASH}$, and this is the reason why a prompt evacuation of ASH is supported by many investigators. We included only patients with hemorrhages of $\leq 14$ days because older ASH are associated with significantly worse functional outcomes $[1,5,6,11,13,14]$.

The correct strategy for massive ASH secondary to $\mathrm{CNV}$ is still under debate. Up to now there have been no standard-of-care recommendations but a variety of therapeutic approaches have been described including intravitreal administration of gas, intravitreal or subretinal application of rt-PA, intravitreal injection of antiVEGF substances, vitrectomy and subretinal clot removal $[11,12]$.

The aim of our retrospective study was a comparison of three surgical treatment options that are available today and to try to elucidate the most effective of them. Nevertheless, this study is a retrospective one without a control group. Between the surgical procedure in the hospital and the follow-up appointment 6 months after surgery, a number of patients failed to attend their follow-up injections: a number of them received their anti-VEGF upload and, if needed, additional intravitreal injections elsewhere.

More than 30 years have elapsed since the early 1990s when rtPA was introduced to facilitate clot liquefaction. RtPA is a serine protease, cleaving plasminogen into active plasmin, which in turn degrades the fibrin matrix constituting blood clots. In addition, other proteins such as hepatocyte growth factor or platelet derived growth 
factor are also cleaved by rtPA $[15,16]$. The use of rtPA has been reported as a surgical adjunct administered both intravitreally and in the subretinal space $[17,18]$. Lewis et al. reported a successful liquefaction of up to $70-80 \%$ of the cases $[19,20]$.

One of the most common therapeutic approaches for ASH is intravitreal injection of rt-PA and gas. This method is minimally invasive and requires less technical equipment and less surgical skills. Heriot was the first to describe a successful pneumatic displacement of ASH with intravitreal injection of rtPA [21,22]. A number of cases and publications demonstrated the effectiveness of the intravitreal application of rt-PA in combination with gas [23-25]. Chen et al. reported success in $60-100 \%$ of patients treated with rt PA and gas [26, 27]. Injection gas or rtPA in non vitrectomized eyes can lead to severe complications like dense vitreous hemorrhage, retinal breaks or even retinal detachments [28-30]. Our study presented two cases of retinal detachment, one of them being in the group of pneumatic displacement without vitrectomy.

VEGF is widely considered the main growth factor leading to increased angiogenesis and vascular leakage [31]. Without anti-VEGF therapy, visual acuity frequently deteriorates because of progression of the underlying CNV. The advent of anti-VEGF pharmacotherapy revolutionized the management of n-AMD. Even though they are not always effective in restoring or improving visual acuity (VA) when a large ASH is present [32], a small number of clinical studies with small study populations showed encouraging results [33-38].

On the one side, the application of rt-PA and gas can help to prevent a toxic effect of ASH by effective displacement from the fovea, and on the other side, the antiVEGF agents can potentially prevent CNV progression. Our study group and various authors have reported positive results $[12,13,25,39,40]$.

With the introduction of small gauge, PPV removal of the vitreous became less invasive [41]. The surgical extraction of the neovascular complex after an ASH was proposed in the 1980s. The submacular blood clot was removed after performing a retinotomy. The results were not promising due to poor visual acuity results (atrophy of the RPE) and frequent complications, e.g. retinal detachment, and the surgical technique was abandoned soon afterwards [42-44]. The results of the Submacular Surgery Trial (SST) showed no clear benefit of surgical removal of AMD-associated hemorrhagic CNV lesions $[45,46]$.

Delivery of rt-PA to the subretinal space can be ensured via subretinal injection, but there are some reservations concerning subretinal injection of rt PA. Surgical manipulations including creation of a retinotomy and injections into the subretinal space can induce considerable damage to the RPE, which leads to the gradual degeneration of photoreceptors and progressive visual impairment [17]. PPV with a subretinal or intravitreal injection of rt-PA and a gas tamponade can effectively displace a submacular hemorrhage away from the fovea. A number of authors reported positive anatomical and functional results [12, 18, 45, 47-50]. Both minimally invasive methods were, in later studies, combined with anti-VEGF therapy [50], allowing for simultaneous treatment of the causative CNV [27]. Hillenkamp and associates compared the effects of an intravitreal or subretinal injection of rt-PA and vitrectomy and gas tamponade in eyes with ASH. They reported that these procedures were more effective than vitrectomy with intravitreal injection of rt-PA and gas tamponade in displacing a submacular hemorrhage. The incidence of postoperative complications consisting of vitreous hemorrhage, retinal detachment and recurrent submacular hemorrhage was higher after a subretinal injection than after intravitreal injection of rt-PA [12]. Even though our study showed that both intravitreal and subretinal injections of rt PA were advantageous for the patient, neither of them proved to be more effective.

In order to address the critical issue of intraoperative and postoperative complications, Cho et al. recommend the less invasive treatment option of anti-VEGF injections as the most effective strategy against ASH associated with AMD. Their study showed no significant therapeutic difference between an anti-VEGF monotherapy and anti-VEGF combined with pneumatic displacement [51].

A new third-generation thrombolytic agent (tenecteplase-TNK), which is a variant of tPA, has been produced by recombinant DNA technology [52]. With a longer half-life and greater fibrin specificity, TNK is potentially more efficacious in thrombus dissolution [53]. A number of studies have shown no retinal toxicity after subretinal TNK injection and positive results after intravitreal injection in humans [54].

Our study excluded PED cases. Fibrovascular PEDs may be difficult to treat, but even these eyes can gain vision after anti-VEGF therapy. A RPE tear may develop in $15 \%$ to $20 \%$ of eyes with PEDs after anti-VEGF therapy; however, vision may stabilize with continued therapy. Atrophy may complicate eyes with PED and nAMD after anti-VEGF therapy, especially in association with complete PED resolution $[55,56]$.

\section{Conclusions}

The management of ASH is controversial, and a standardized management protocol still does not exist. Various factors can determine the final outcome and the 
prognosis of VA. Age, size, duration of the hemorrhage and patients' health status are significant factors. As discussed above, a subretinal bleeding can have devastating consequences on the health and integrity of the photoreceptors and the RPE so that even a prompt evacuation of the ASH in combination with anti-VEGF agents, which constitute the mainstay of CNV treatment, could not significantly change and improve the VA. We have demonstrated that the three well-known and established treatment methods help to improve morphology and BCVA, but none of them had any clear advantage over the others. The continuation of the antiVEGF regimen is very important to further suppress the CNV formation and activity. Patients health status and treatment costs have to be taken into account. In light of our findings, we can support pneumatic displacement combined with intravitreal anti-VEGF as a treatment option due to its minimally invasive character and non-inferior anatomical and functional results.

Our study has several limitations, including its retrospective nature and the small number of patients in group C. Moreover, there was no control study group without any treatment.

\section{Acknowledgements}

We would like to thank Vasyl Druchkiv for helping us with the statistical analysis.

\section{Authors' contributions}

CG: Setup of the table for anonymized patient data. Contributing to the manuscript. Data entry and analyzing. SD: Setup of the table for anonymized patient data. Contributing to the manuscript. Data entry and analyzing. KUBS: Interpretation of the data and contribution to the manuscript. PS: Data entry and analyzing, contribution to the manuscript. TK: Interpretation of the data and contribution to the manuscript. MS: Interpretation of the data and contribution to the manuscript. CS: Interpretation of the data and contribution to the manuscript. All authors read and approved the final manuscript.

\section{Funding}

There are no external funding sources. All work has been done in-house.

\section{Availability of data and materials}

The datasets used and analyzed during the current study are available from the corresponding author on reasonable request.

\section{Ethics approval and consent to participate}

We report a study where only retrospective anonymous data was taken into account, and therefore, there is no need for ethics approval. The investigation adhered to the tenets of the declaration of Helsinki.

\section{Consent for publication}

Not applicable.

\section{Competing interests}

The authors declare that they have no competing interests.

\section{Author details}

1 Department of Ophthalmology, University Medical Center Hamburg-Eppendorf (UKE), Hamburg, Germany. ${ }^{2}$ Department of Ophthalmology, Eberhard Karls University Medical Center, Tübingen, Germany.

Received: 22 November 2019 Accepted: 21 June 2020 Published online: 02 July 2020

\section{References}

1. Avery RL, Fekrat S, Hawkins BS, Bressler NM. Natural history of subfoveal subretinal hemorrhage in age-related macular degeneration. Retina. 1996;16(3):183-9.

2. Bhisitkul RB, Winn BJ, Lee OT, Wong J, Pereira DS, Porco TC, He X, Hahn P, Dunaief $J$ L. Neuroprotective effect of intravitreal triamcinolone acetonide against photoreceptor apoptosis in a rabbit model of subretinal hemorrhage. Invest Ophthalmol Vis Sci. 2008;49:4071-7.

3. El Baba F, Jarrett WH, Harbin TS, Fine SL, Michels RG, Schachat AP, Green WR. Massive hemorrhage complicating age-related macular degeneration: clinicopathologic correlation and role of anticoaggulants. Ophthalmology. 1986;93:1581-92.

4. Gillies A, Lahav M. Absorption of retinal and subretinal hemorrhages. Ann Ophthalmol. 1983;15:1068-74.

5. Glatt $\mathrm{H}$, Machemer R. Experimental subretinal hemorrhage in rabbits. Am J Ophthalmol. 1982:94:762-73.

6. Toth CA, Morse LS, Hjemeland LM, Landers MB. Fibrin early retinal damage after experimental subretinal hemorrhage. Arch Ophthalmol. 1991;109:723-9.

7. Hasegawa T, Otani A, Sasahara M, Gotoh N, Ooto S, Tamura H, Yamashiro K, Tsujikawa A, Yoshimura N. Prognostic factors of vitreous hemorrhage secondary to exudative age-related macular degeneration. Am J Ophthalmol. 2010;149:322-9.

8. Martin DF, Maguire MG, Fine SL, Ying GS, Jaffe GJ, Grunwald JE, Toth C, Redford M, Ferris FL. Ranibizumab and bevacizumab for treatment of neovascular age-related macular degeneration: two-year results. Ophthalmology. 2012;119:1388-98.

9. Scupola A, Coscas G, Soubrane G, Balestrazzi E. Natural history of macular subretinal hemorrhage in age-related macular degeneration. Ophthalmologica. 1999;213(2):97-102.

10. Steel DH, Sandhu SS. Submacular haemorrhages associated with neovascular age-related macular degeneration. Br J Ophthalmol. 2011;95:1051-7.

11. Bennett SR, Folk JC, Blodi CF, Klugman M. Factors prognostic of visual outcome in patients with subretinal hemorrhage. Am J Ophthalmol. 1990;109(1):33-7.

12. Hillenkamp J, Surguch V, Framme C, Gabel VP, Sachs HG. Management of submacular hemorrhage with intravitreal versus subretinal injection of recombinant tissue plasminogen activator. Graefes Arch Clin Exp Ophthalmol. 2010;248(1):5-11.

13. Hattenbach LO, Klais C, Koch FH, Gümbel HO. Intravitreous injection of tissue plasminogen activator and gas in the treatment of submacular hemorrhage under various conditions. Ophthalmology. 2001;108:1485-92.

14. Hochman MA, Seery CM, Zarbin MA. Pathophysiology and management of subretinal hemorrhage. Surv Ophthalmol. 1997;42:195-213.

15. Mars WM, Zarnegar R, Michalopoulos GK. Activation of hepatocyte growth factor by the plasminogen activators UPA and tPA. Am J Pathol. 1993;143:949-58.

16. Su EJ, Fredriksson L, Geyer M, et al. Activation of PDGF-CC by tissue plasminogen activator impairs blood-brain barrier integrity during ischemic stroke. Nat Med. 2008;14:731-7.

17. Olivier S, Chow DR, Packo KH, MacCumber MW, Awh CC. Subretinal recombinant tissue plasminogen activator injection and pneumatic displacement of thick submacular hemorrhage in age-related macular degeneration. Ophthalmology. 2004;11:1201-8.

18. Singh RP, Patel C, Sears JE. Management of subretinal macular haemorrhage by direct administration of tissue plasminogen activator. $\mathrm{Br} J$ Ophthalmol. 2006;90:429-31.

19. Lewis H. Intraoperative fibrinolysis of submacular hemorrhage with tissue plasminogen activator and surgical drainage. Am J Ophthalmol. 1994;118(559-568):12.

20. Peyman GA, Nelson NC Jr, Alturki W, Blinder KJ, Paris CL, Desai UR, Harper CA 3rd. Tissue plasminogen activating factor assisted removal of subretinal hemorrhage. Ophthalmic Surg. 1991;22:575-82.

21. Heriot WJ. Further experience in management of submacular hemorrhage with intravitreal tPA. In: Proceedings of the update on macular surgery. American Academy of Ophthalmology, San Francisco; 1997. pp 82-84. 
22. Mozaffarieh M, Heinzl H, Sacu S, Wedrich A. In-patient management and treatment satisfaction after intravitreous plasminogen activator injection. Graefes Arch Clin Exp Ophthalmol. 2006;244(11):1421-8.

23. Hassan AS, Johnson MW, Schneiderman TE, Refillo CD, Tornambe PE, Poliner LS, Blodi BA, Elner SG. Management of submacular hemorrhage with intravitreous tissueplasminogen activator injection and pneumatic displacement. Ophthalmology. 1999;106(10):1900-6.

24. Hesse L, Kroll P. Successful treatment of acute subretinal hemorrhage in age-related macular degeneration by combined intravitreal injection of recombinant tissue plasminogen activator and gas. Adv Ther. 1997;14(5):275-80.

25. Hesse L, Schmidt J, Kroll P. Management of acute submacular hemorrhage using recombinant tissue plasminogen activator and gas. Graefes Arch Clin Exp Ophthalmol. 1999;237:273-7.

26. Chen CY, Hooper C, Chiu D, Chamberlain M, Karia N, Heriot WJ. Management of submacular hemorrhage with intravitreal injection of tissue plasminogen activator and expansile gas. Retina. 2007;27:321-8.

27. Meyer CH, Scholl HP, Eter N, Helb HM, Holz FG. Combined treatment of acute subretinal haemorrhages with intravitreal recombined tissue plasminogen activator, expansile gas and bevacizumab. Acta Ophthalmol. 2008;86(5):490-4.

28. Kimura S, Morizane Y, Hosokawa M, et al. Submacular hemorrhage in polypoidal choroidal vasculopathy treated by vitrectomy and subretinal tissue plasminogen activator. Am J Ophthalmol. 2015;159(4):683-9.

29. Kokame GT. Vitreous hemorrhage after intravitreal tissue plasminogen activator (tPA) and pneumatic displacement of submacular hemorrhage. Am J Ophthalmol. 2000;129:456-7.

30. Ohji M, Saito Y, Hayashi A, Lewis JM, Tano Y. Pneumatic displacement of subretinal hemorrhage without tissue plasminogen activator. Arch Ophthalmol. 1998;1 16:1326.

31. Thomas M, Mousa SS, Mousa SA. Comparative effectiveness of aflibercept for the treatment of patients with neovascular age-related macular degeneration. Clin Ophthalmol. 2013;7:495-501.

32. Kiernan DF, Hariprasad SM, Rusu IM, Mehta SV, Mieler WF, Jager RD. Epidemiology of the association between anticoagulants and intraocular hemorrhage in patients with neovascular age-related macular degeneration. Retina. 2010;30(10):1573-8.

33. Cho HJ, Koh KM, Kim HS, Lee TG, Kim CG, Kim JW. Anti- vascular endothelial growth factor monotherapy in the treatment of submacular hemorrhage secondary to polypoidal choroidal vasculopathy. Am J Ophthalmol. 2013;156:524-31.

34. Heier JS, Brown DM, Chong V, et al. Intravitreal aflibercept (VEGF trap-eye) in wet age-related macular degeneration. Ophthalmology. 2012;119(12):2537-48.

35. Ip MS, Scott IU, Brown GC, et al. Anti-vascular endothelial growth factor pharmacotherapy for age-related macular degeneration: a report by the American Academy of Ophthalmology. Ophthalmology. 2008;115:1837-46.

36. Kim JH, Chang YS, Kim JW, Kim CG, Yoo SJ, Cho HJ. Intravitreal anti-vascular endothelial growth factor for submacular hemorrhage from choroidal neovascularization. Ophthalmology. 2014;121:926-35.

37. Martin DF, Maguire MG, Ying GS, Grunwald JE, Fine SL, Jaffe GJ. Ranibizumab and bevacizumab for neovascular age-related macular degeneration. N Engl J Med. 2011;364(20):1897-908.

38. Schouten JS, La Heij EC, Webers CA, Lundqvist IJ, Hendrikse F. A systematic review on the effect of bevacizumab in exudative age-related macular degeneration. Graefes Arch Clin Exp Ophthalmol. 2009;247:1-11.

39. Guthoff R, GuthoffT, Meigen T, Goebel W. Intravitreous injection of bevacizumab, tissue plasminogen activator, and gas in the treatment of submacular hemorrhage in age-related macular degeneration. Retina. 2011;31:36-40.
40. Treumer F, Klatt C, Roider J, Hillenkamp J. Subretinal co-application of recombinant tissue plasminogen activator and Bevacizumab for neovascular age-related macular degeneration with submacular hemorrhage. $\mathrm{Br}$ J Ophthalmol. 2010;94:48-53.

41. Haas A, Seidel G, Steinbrugger I, Maier R, Gasser-Steiner V, Wedrich A, Weger M. Twenty-three-gauge and 20-gauge vitrectomy in epiretinal membrane surgery. Retina. 2010;30(1):112-6.

42. De Juan E, Machemer R Jr. Vitreous surgery for hemorrhagic and fibrous complication of age-related macular degeneration. Am J Ophthalmol. 1988;105:25-9.

43. Gabel VP. Subretinal lavage in fresh hemorrhage in macular degeneration. Fortschr Ophthalmol. 1991;88:135-7.

44. Vander JF, Federman JL, Greven C, Slusher MM, Gabel VP. Surgical removal of massive subretinal hemorrhage associated with age-related macular degeneration. Ophthalmology. 1991;98:23-7.

45. Bressler NM, Bressler SB, Childs AL, et al. Surgery for hemorrhagic choroidal neovascular lesions of age-related macular degeneration: ophthalmic findings: SST report No. 13. Ophthalmology. 2004;111:1993-2006.

46. Heiduschka P, Fietz H, Hofmeister S, et al. Penetration of Bevacizumab through the retina after intravitreal injection in the monkey. Invest Ophthalmol Vis Sci. 2007;48:2814-23.

47. Haupert CL, McCuen BW, Jaffe GJ, Steuer ER, CoxTA, Toth CA, Fekrat S, Postel EA. Pars plana vitrectomy, subretinal injection of tissue plasminogen activator, and fluid-gas exchange for displacement of thick submacular hemorrhage in age-related macular degeneration. Am J Ophthalmol. 2001;131:208-15.

48. Saika S, Yamanaka A, Yamanaka A, et al. Subretinal administration of tissue-typeplasminogen activator to speed the drainage of subretinal hemorrhage. Graefes Arch Clin Exp Ophthalmol. 1998;236:196-201.

49. Thompson JT, Sjaarda RN. Vitrectomy for the treatment of submacular hemorrhages from macular degeneration: a comparison of submacular hemorrhage/membrane removal and submacular tissue plasminogen activator- assisted pneumatic displacement. Trans Am Ophthalmol Soc. 2005;103:98-107.

50. Treumer F, Roider J, Hillenkamp J. Long-term outcome of subretinal coapplication of rtPA and bevacizumab followed by repeated intravitreal antiVEGF injections for neovascular AMD with submacular haemorrhage. Br J Ophthalmol. 2012;96(5):708-13.

51. Cho HJ, Koh KM, Kim JH, Kim HS, Han JI, Lew YJ, Lee TG, Kim JW. Intravitreal ranibizumab injections with and without pneumatic displacement for treating submacular hemorrhage secondary to neovascular agerelated macular degeneration. Retina. 2015;35:205-12.

52. Davydov L, Cheng JW. Tenecteplase: a review. Clin Ther. 2001;23:982-97.

53. Rowley SA, Vijayasekaran S, Yu PK, McAllister IL, Yu DY. Retinal toxicity of intravitreal tenecteplase in the rabbit. Br J Ophthalmol. 2004;88:573-8.

54. McAllister IL, Chen SD, Patel Jl, Fleming BL, Dao-Yi Yu. Management of submacular haemorrhage in age-related macular degeneration with intravitreal tenecteplase. Br J Ophthalmol. 2010;94:260-1.

55. Khanani AM, Eichenbaum D, Schlottmann PG, Tuomi L, Sarraf D. Optimal management of pigment epithelial detachments in eyes with neovascular age-related macular degeneration. Retina. 2018;38(11):2103-17.

56. Kwon YH, Lim SJ, Jeung WJ, You YS, Kim SH, Kwon OW. Subretinal tenecteplase injection in a submacular hemorrhage from polypoidal choroidal vasculopathy: a case report. Retin Cases Brief. 2012;6:400-5.

\section{Publisher's Note}

Springer Nature remains neutral with regard to jurisdictional claims in published maps and institutional affiliations. 